\title{
QUALITY OF LIFE, PAIN, ANXIETY AND DEPRESSION IN PATIENTS SURGICALLY TREATED WITH CANCER OF RECTUM
}

\author{
Qualidade de vida, dor, depressão e ansiedade em pacientes operados por câncer de reto \\ Letácio José Freire SANTOS, João Batista dos Santos GARCIA, Jairo Sousa PACHECO, \\ Érica Brandão de Morais VIEIRA, Alcione Miranda dos SANTOS
}

Study carried out in the Federal University of Maranhão, Maranhão Institute of Oncology, Hospital Aldenora Bello, and in the Oncology Unit Dr. Raymundo Matos Serrão, Hospital Dr. Tarquínio Lopes Filho, São Luis, MA, Brazil.

HEADINGS - Cancer. Pain. Life quality. Depression. Anxiety.
ABSTRACT - Background - The rectum cancer is associated with high rates of complications and morbidities with great impact on the lives of affected individuals. Aim: To evaluate quality of life, pain, anxiety and depression in patients treated for medium and lower rectum cancer, submitted to surgical intervention. Methods: A descriptive cross-sectional study. Eighty-eight records of patients with medium and lower rectum cancer, submitted to surgical intervention were selected, and enrolled. Forty-seven patients died within the study period, and the other 41 were studied. Question forms EORTC QLQ-C30 and EORTC QLQCR38 were used to assess quality of life. Pain evaluation was carried out using the Visual Analogical Scale, depression and anxiety were assessed through Depression Inventories and Beck's Anxiety, respectively. The correlation between pain intensity, depression and anxiety was carried out, and between these and the EORTC QLQ-C30 General Scale for Health Status and overall quality of life, as well as the EORTC QLQ-CR38 functional and symptom scales. Results: Of the 41 patients of the study, $52 \%$ presented pain, depression in $47 \%$, and anxiety in $39 \%$. There was a marking positive correlation between pain intensity and depression. There was a moderate negative correlation between depression and general health status, and overall quality of life as well as pain intensity with the latter. There was a statistically significant negative correlation between future depression perspective and sexual function, and also a strong positive correlation between depression and sexual impairments. A positive correlation between anxiety and gastro-intestinal problems, both statistically significant, was observed. Conclusion: Evaluation scales showed detriment on quality life evaluation, besides an elevated incidence of pain, depression, and anxiety; a correlation among these, and factors which influence on the quality of life of post-surgical medium and lower rectum cancer patients was observed.

\section{Correspondence:}

Letácio José Freire Santos

E-mail: letaciofreire@icloud.com

Financial source: none

Conflicts of interest: none

Received for publication: 01/12/2013 Accepted for publication: 18/02/2014

DESCRTIORES - Câncer. Dor. Qualidade de vida. Depressão. Ansiedade.
RESUMO - Racional - O câncer de reto está associado com altos índices de complicações e morbidade com grande impacto na vida dos indivíduos por ele acometidos. Objetivo: Avaliar a qualidade de vida, dor, depressão e ansiedade em pacientes com câncer de reto médio e inferior, submetidos à intervenção cirúrgica com intenção curativa. Métodos: Trata-se de estudo descritivo, transversal. Foram selecionados inicialmente 88 prontuários de pacientes com câncer de reto médio e inferior submetidos à operação radical. Destes, 47 faleceram no período e os 41 remanescentes foram convocados para o estudo. Avaliouse a qualidade de vida pelos questionários EORTC QLQ-C30 e O EORTC QLQ-CR38, e a dor através da Escala Visual Analógica; para depressão e ansiedade utilizaram-se os Inventários de Depressão e Ansiedade de Beck respectivamente. Foi feita a correlação entre intensidade da dor, depressão, ansiedade entre estes e a Escala de Estado Geral de Saúde e Qualidade de Vida Global do EORTC QLQ-C30, além das escalas funcionais e de sintomas do EORTC QLQ-CR38. Resultados: Dos 41 pacientes que compareceram, $52 \%$ apresentaram dor, $47 \%$ depressão e $39 \%$ ansiedade. Houve correlação positiva forte entre intensidade dolorosa e depressão, correlação negativa moderada entre depressão e estado geral de saúde e qualidade de vida global, e desta com a intensidade dolorosa. Houve correlação negativa estatisticamente significante entre depressão perspectiva futura e função sexual, assim como correlação positiva forte entre depressão e problemas sexuais. Observou-se correlação positiva entre ansiedade e problemas gastrointestinais e sexuais, ambos estatisticamente significantes. Conclusão: Houve prejuízo nas escalas de avaliação da qualidade de vida. Além da alta prevalência de dor, depressão e ansiedade, observou-se correlações entre estes e fatores que influenciam a qualidade de vida dos portadores de câncer de reto médio e inferior após a operação.

\section{INTRODUCTION}

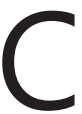
olorectal cancer has a variable geographic distribution and is related to risk factors, such as heredity, dietary pattern, obesity and smoking ${ }^{4}$. It is the second most prevalent tumor worldwide?. In Brazil, estimate for 2012 was 30,140 new cases. From these, 14,180 would affect males and 15,960 females. In the state of Maranhão, the estimate for the same year was 200 new cases, from these 90 affecting males. It is the fourth most frequent type, being second only to prostate, lungs and stomach cancer. Among females, this is the third 
more frequent tumor, second only to breast and cervical cancer, with the incidence of 110 cases $^{23}$

The classification of rectal tumors according to their location influences neoadjuvant and/or surgical treatment. Lower third tumors (up to $5 \mathrm{~cm}$ of the anal margin) and medium third tumors (5.1 to $10 \mathrm{~cm}$ of the anal margin), if incipient, are only treated with surgery. If advanced, they are treated with radiochemotherapy plus surgical procedure. Upper third tumors (10.1 to $15 \mathrm{~cm}$ of the anal margin) have biological behavior and treatment similar to colon tumors ${ }^{11,29}$.

Better understanding of rectal cancer natural history associated to the concept of negative lateral margin and introduction of careful dissection along embryonic planes has decreased recurrence from $37 \%$ in the 1980's to less than $10 \%$ today in specialized centers, and global survival above $60 \%$ in five years. The acceptance of $1 \mathrm{~cm}$ negative distal margin and the technological progress of surgical staplers have increased the number of conservative surgeries, currently around $70 \%-75 \%$, preserving sphincter function and fecal continence ${ }^{6,10}$.

However, curative treatment of mid and low rectal cancer implies high levels of complications and morbidity which result in long term objective and subjective changes ${ }^{8}$. Most important are major anatomofunctional disorders and particularities regarding behavior and patients' level of adaptation to the disease, because there is the constant threat of life expectation, in addition to conditions imposed by diagnostic procedures, symptoms and type of treatment ${ }^{15,18}$.

Among symptoms, pain is especially referred by cancer patients in general, and its prevalence varies with disease staging and site $^{14}$. Specifically for rectal cancer, there is increased pain in advanced disease, with persistence in $30 \%$ of patients who require long term analgesia ${ }^{15}$. Due to multidimensional cancer pain aspects and complex inter-relations (physiological, psychological, cognitive and social), adequate pain evaluation and treatment are critical because pain experience of cancer patients is constantly related to distress, depression, anxiety, fear, negative mood and suicide ideas. Pain persistence increases patients' concern with regard to disease progression, especially when it is underestimated by health professionals ${ }^{14,30}$.

Additionally, depression and anxiety are independently present in 30\%-39\% of advanced cancer patients ${ }^{27}$. So, psychiatric disorders should be investigated because diagnosis and treatment are very often omitted in such patients, affecting their quality of life (QL), impairing functional capacity and bringing physical and emotional limitations ${ }^{28}$.

The dimensioning of $\mathrm{QL}$ and of variables influencing it in rectal cancer patients after standard therapy, also allows the evaluation and diagnosis of treatment adverse effects $^{8}$. So, it is relevant for the daily clinical practice the adoption of approaches to minimize pain, functional damage and psychosocial repercussions, especially anxiety and depression.

In Brazil, we lack studies of this nature, which has motivated this study, the objective of which is to evaluate $\mathrm{QL}$, presence of pain, anxiety and depression and their possible correlations in patients with mid and low rectal cancer submitted to surgical intervention with curative intention.

\section{METHODS}

This study was approved by the Ethics Committee under n. 00687/10 and all patients have signed the Free and Informed Consent Term.

This is a descriptive, transversal study carried out in the Maranhão Institute of Oncology, Hospital Aldenora Bello, and in the Oncology Unit Dr. Raymundo Matos Serrão, Hospital Dr. Tarquínio Lopes Filho, both reference cancer treatment centers in São Luis, State of Maranhão, Brazil.

Non probabilistic sample was made up of patients selected after a query in medical records databases of the above-mentioned hospitals, all admitted with CID-10 C20 (rectal cancer) from January 2006 to December 2010. We have selected 88 medical records of patients with mid and low rectal cancer, however 47 had already died, remaining 41 patients operated on with curative intention (anterior rectal dissection or abdominoperineal amputation with total mesorectal excision), submitted or not to neoadjuvant or adjuvant radiochemotherapy who were invited to the study (Figure 1). Exclusion criteria were patients with local or distant recurrence, those treated with local excision and those who were not found (have not returned for follow up).
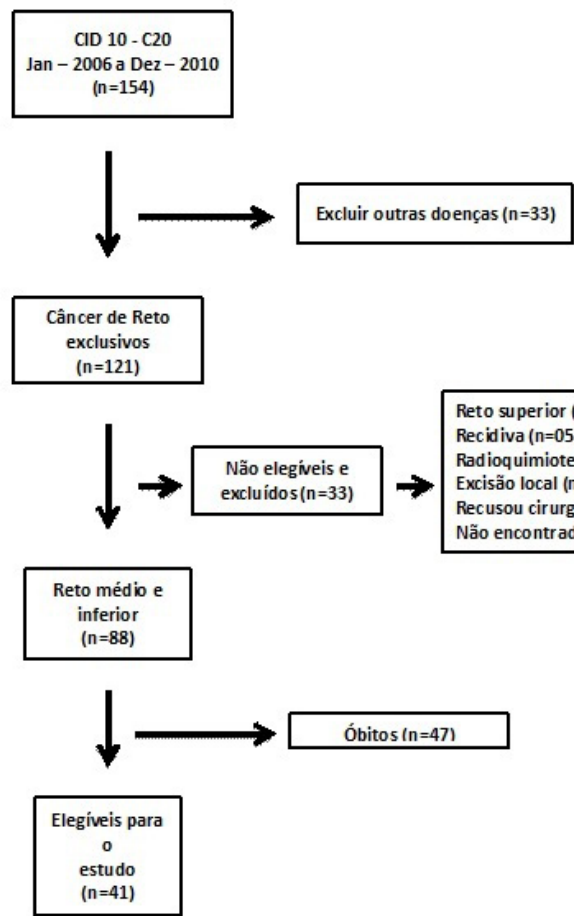

FIGURE 1 - Flowchart of patients' selection process

As data collection sources, we have used information obtained from patients' medical records to fill the protocol card specifically developed for rectal tumors and including sociodemographic variables, data related to symptoms, diagnosis, staging, treatment and complications. After checking inclusion criteria, an outpatient clinical interview was carried out to complement the protocol card. Karnofsky status performance scale was applied ${ }^{22}$, in addition to validated questionnaires for $\mathrm{QL}$, pain, depression and anxiety. Two questionnaires developed by the European Organization for Research and Treatment of Cancer (EORTC), validated for Brazil were used ${ }^{24}$.

The first, EORTC QLQ-C30, provides generic evaluation of cancer patients. It is made up of five functional scales (physical, routine, cognitive, emotional and social); three symptoms scales (fatigue, pain and nausea/vomiting); six items evaluating different aspects of global quality of life (dyspnea, insomnia, anorexia, constipation, diarrhea and financial problems); and two questions about general health status and global quality of life ${ }^{1}$.

The second EORTC QLQ-CR38 is an additional questionnaire evaluating specific rectal cancer symptoms and side effects related to different types of treatment. It is 
made up of 38 items. It incorporates two functional scales: body image and sexuality; seven symptoms scales: voiding problems, symptoms related to the gastrointestinal tract, chemotherapy side-effects, defecation problems, problems related to stoma and sexual problems. Other items are future perspective and weight loss. Both questionnaires have four alternative answers: no, mild, moderate and severe, except for the global health evaluation and quality of life scale (GHE/GQL) of the EORTC QLQ-C30 questionnaire which has seven alternatives going from lousy to excellent.

Mean results of items contributing to the scale, the Raw Score, were obtained, which suffer linear transformation in a scale from zero to 100 . High functional scales scores represent high function levels, while high symptoms scales scores represent significant exacerbation of symptoms or distress ${ }^{25}$. To help the evaluation of such scores, it was suggested that scores above 50 would indicate satisfactory quality and function and inadequate symptoms control.

Pain intensity was measured with the Visual Analog Scale (VAS) ${ }^{12}$, which submits patients to a non-graded line where one end corresponds to no pain and the opposite end represents the worst imaginable pain, in addition to data about pain onset.

Beck Depression Inventory (BDI) and Beck Anxiety Inventory (BAI) were used to measure depression and anxiety, respectively. Both are adapted and validated for Brazil and have excellent reliability levels ${ }^{7}$. Inventories were applied according to guidelines of the Portuguese version. They are made up of 21 items, with four alternative answers, according to increasing manifestation of symptoms severity. A total score is obtained adding all items checked by the respondent. Highest possible score is 63 points. For this study, the following scores for depression were considered: absence or minimum depression (0.9), mild (10-16), moderate (17-29) and severe (30-63), while anxiety levels were: minimum (0-7), mild (8-15), moderate (16-25) and severe $(26-63)^{3}$

Data were organized in Excel 2007 $®$ spreadsheets and statistical tests were analyzed by the Statistical Package for Social Sciences (SPSS) version 17.0. Descriptive analysis was carried out. Absolute and relative frequency measures were used to quantify categorical variables, and central trend (mean) and variability (standard deviation) measures were used for qualitative variables. Variables distribution was checked with the Shapiro-Wilk test. When abnormalities were observed the Spearman correlation test was used. Correlation coefficient below 0.10 indicated no relation; between 0.10 and 0.30 weak relation; between 0.30 and 0.50 moderate relation and above 0.50 strong relation. Significance level for all statistical tests was $5 \%(p<0.05)$.

\section{RESULTS}

Questions were well accepted and understood by most patients. Sample was made especially by females. Mean age was $53.7 \pm 15.4$ years. Most patients (25) lived with companion, nine were single, three divorced and four widowers. As to education, 12 were illiterate, 17 had basic education, 10 had high school and only two had completed university. From these, 23 patients were catholic and 18 evangelical.

Mean time between surgical procedure and interview was $28.7 \pm 18.7$ months. Mean functional capacity evaluation (Karnofsky) was high (86.5 \pm 8.8$)$. As to diagnosis, nine (23\%) were stage I, 13 (34.2\%) IIa, one (2.6\%) IIb, nine (23\%) IIIb and six (15.8\%) IIIc. There has been predominance of medium third rectal tumors (23 or $56 \%$ ). Remaining 18 cases were lower third tumors (44\%). Twenty-seven patients (65.8\%) were submitted to neoadjuvant radiochemotherapy and 2 (4.9\%) exclusively to radiotherapy. Eight patients (19.5\%) were submitted to adjuvant radiochemotherapy and 26 (63.4\%) exclusively to chemotherapy. Postoperative complications were present in 14 (34\%) patients. Sphincter preservation was observed in 20 (49\%) patients. Pain was referred by 21 patients (52\%) with mean intensity of $3.8 \pm 2.4$. From these, 19 (90.5\%) had pain onset three months before or longer. Twenty-two (53.7\%) had minimum or absent depression, nine (21.9\%) mild depression, eight (19.5\%) moderate depression and two (4.9\%) severe depression. Minimum anxiety level was seen in 25 (60.9\%) patients, mild in 11 (26.9\%) patients, moderate in 4 (9.8\%) patients and severe in 1 (2.4\%) patient (Table 1).

TABLE 1 - Pain prevalence, duration and intensity, anxiety and depression classification by Beck inventory in mid and low rectal cancer patients after surgical curative treatment. São Luis, 2012.

\begin{tabular}{|c|c|c|}
\hline Variables & $\mathbf{n}$ & $\%$ \\
\hline $\begin{array}{c}\text { Presence of pain } \\
\text { No }\end{array}$ & 19 & 47.5 \\
Yes & 21 & 52.5 \\
\hline $\begin{array}{c}\text { Pain duration } \\
\text { < } 3 \text { months }\end{array}$ & 2 & \\
= 3 months & 19 & 9.5 \\
\hline $\begin{array}{c}\text { Pain intensity } \\
\text { Depression }\end{array}$ & $3.8 \pm 2.4^{*}$ & 90.5 \\
\hline Absent or minimum & 22 & \\
\hline Mild & 9 & 53.7 \\
Moderate & 8 & 21.9 \\
Severe & 2 & 19.5 \\
\hline Absent or minimum & 25 & 4.9 \\
Mild & 11 & 60.9 \\
Moderate & 4 & 25.9 \\
Severe & 1 & 9.8 \\
\hline
\end{tabular}

* Mean and standard deviation

Quality of life scores and EORTC QLQ-C30 scores are shown. Results of functional scales, symptoms and general health status evaluation meet satisfactory quality and function criteria and adequate symptoms control (Table 2).

TABLE 2 - EORTC QLQ-C30 results of mid and low rectal cancer patients after curative surgical treatment. São Luis, 2012.

\begin{tabular}{|c|c|c|}
\hline Variables & n & meam (Sd) \\
\hline GHS/GQL* & 41 & $79.8(8.1)$ \\
\hline FUNCTIONAL & & \\
Physical Function & 41 & $84.9(22.7)$ \\
Routine Performance & 41 & $66.6(30.5)$ \\
Emotional Function & 40 & $75.9(21.2)$ \\
Cognitive Function & 41 & $87.1(24.4)$ \\
Social Function & 41 & $70.5(33.5)$ \\
\hline SYMPTOMS & & \\
Fatigue & 41 & $20.4(24.5)$ \\
Nausea \& Vomiting & 41 & $8.7(20.3)$ \\
Pain & 41 & $22(27.5)$ \\
SIMPLE ITEMS & & \\
Dyspnea & 41 & $8.1(19.3)$ \\
Insomnia & 41 & $25.6(38.8)$ \\
Loss of appetite & 41 & $10.5(22.9)$ \\
Constipation & 41 & $11.4(27.5)$ \\
Diarrhea & 41 & $4.9(19.1)$ \\
Financial Problems & 40 & $32.0(36.7)$ \\
\hline
\end{tabular}

*General Health Status and Global Quality of Life

Results of the evaluation of functional and symptoms scales of the EORTC QLQ-CR38 questionnaire have shown more attention to sexual function and satisfaction, as well as future perspective with borderline index (Table 3). 
TABLE 3 - Description of EORTC QLQ-C38 quality of life tool for mid and low rectal cancer patients after curative surgical treatment. São Luis, 2012.

\begin{tabular}{|c|c|c|}
\hline \multirow{2}{*}{\multicolumn{3}{|c|}{$\begin{array}{l}\text { Variables } \\
\text { FUNCTIONAL }\end{array}$}} \\
\hline & & \\
\hline Body Image & 40 & $61.4(30.9)$ \\
\hline Sexual Function & 40 & $30.4(31.3)$ \\
\hline Sexual Satisfaction & 41 & $13.0(26.8)$ \\
\hline Future Perspective & 41 & $50.9(34.0)$ \\
\hline \multicolumn{3}{|l|}{ SYMPTOMS } \\
\hline Voiding Problems & 41 & $18.9(21.0)$ \\
\hline Gastrointestinal Symptoms & 41 & $4.9(19.1)$ \\
\hline Chemotherapy Effects & 39 & $11.1(15.5)$ \\
\hline Sexual Problems & 41 & $44.0(40.7)$ \\
\hline Ostomy Problems & 24 & $34.0(18.8)$ \\
\hline Defecation Problems & 15 & $28.4(23.1)$ \\
\hline Weight Loss & 41 & $16.3(28.0)$ \\
\hline
\end{tabular}

There is strong positive correlation between pain intensity and depression, and moderate negative correlation between pain intensity and GHS/GQL. There is moderate negative statistically significant correlation between depression and GHS/GQL (Table 4).

TABLE 4 - Correlation between pain intensity, anxiety, depression and GHS/GQL** of mid and low rectal cancer patients after curative surgical treatment. São Luis, 2012

\begin{tabular}{|c|c|c|c|c|}
\hline & Pain Intensity & Depression & Anxiety & EGS/QVG** \\
\hline $\begin{array}{c}\text { Pain } \\
\text { Intensity }\end{array}$ & 1.0000 & & & \\
\hline $\begin{array}{c}\text { Level of Depression } \\
\text { Level of Anxiety }\end{array}$ & $0.6100^{*}$ & 1.0000 & 0.2964 & \\
GHS/GQL & 0.3410 & & 1.0000 & \\
\hline & $-0.4472^{\star}$ & $-0.4434^{*}$ & -0.2245 & 1.0000 \\
\hline
\end{tabular}

Spearman Correlation * $\mathrm{p}<0.05$

GHS/GQL** General Health Status and Global Quality of Life

In correlations between pain intensity, depression, anxiety and functional and symptoms scales of the EORTC QLQ-CR38 questionnaire, one should stress the strong negative correlation between depression and sexual function; moderate negative correlation between depression and future perspective. There is strong positive correlation between depression and sexual problems. There is moderate positive correlation between anxiety and gastrointestinal problems and moderate positive correlation between anxiety and sexual problems. All of them are statistically significant (Table 5 ).

TABLE 5 - Correlation between pain intensity, depression, anxiety and functional and symptoms scales of the EORTC QLQ-CR38 questionnaire in mid and low rectal cancer patients after curative surgical treatment. São Luis, 2012

\begin{tabular}{|l|c|c|c|}
\hline & Pain Intensity & Depression & Anxiety \\
\hline FUNCTIONAL & & & \\
\hline Body Image & -0.0163 & -0.3663 & -0.1647 \\
\hline Sexual Function & 0.0138 & $-0.5175^{*}$ & -0.2911 \\
\hline Sexual Satisfaction & -0.1059 & -0.3945 & $-0,2048$ \\
\hline Future Perspective & -0.1347 & $-0.4453^{*}$ & -0.2299 \\
\hline SYMPTOMS & & & \\
\hline Voiding Problems & 0.0410 & -0.0031 & -0.0183 \\
\hline Gastrointestinal Symptoms & -0.0683 & 0.2821 & $0.3975^{*}$ \\
\hline Chemotherapy Effect & 0.3212 & 0.1583 & 0.2567 \\
\hline Sexual Problems & 0,2116 & $0.5198^{*}$ & $0.4017^{*}$ \\
\hline Ostomy Problems & -0.0920 & -0.1999 & -0.3458 \\
\hline Defecation Problems & 0.0000 & 0.2043 & 0.3214 \\
\hline Weight Loss & -0.1590 & 0.3402 & 0.0526 \\
\hline Spearman Correlation* $\mathrm{p}<0.05$ & & & \\
\hline
\end{tabular}


is superiority of cognitive, sexual and emotional function and vitality in those without ostomy ${ }^{2}$. So, strong associations of psychological problems and sexual dysfunction have been reported with high levels of depression, anxiety and other negative complaints associated to somatic manifestations ${ }^{17}$.

Our study has found a strong correlation between depression and future perspective, in addition to a trend to low EORTC QLQ-CR38 questionnaire scores. This is justified by the short post-treatment period of most patients. In the beginning of the therapy there is higher risk of recurrence, influenced by the severity of the disease and consequent aggressive treatment, which has been applied to most patients. During this period, there is negative influence of depression in the maintenance of interpersonal relationships, which induces patients to loneliness and hopelessness ${ }^{27}$. However physcological manifestations of well-being, hope and future perspective tend to improve after 36 months of treatment ${ }^{23}$.

There has also been high prevalence of anxiety (39.1\%), as compared to other colorectal cancer studies 20,28 , however, its correlation with pain intensity, depression and GHS/GQL was weak without statistical significance. Colorectal cancer diagnosis associated to symptoms and treatment effects promote psychological vulnerability, especially the association of depression and anxiety, inducing low QL expectation, but such results may change due to the transient characteristic of symptoms along time ${ }^{28}$.

The association of symptoms and psychological disorders is very evident among colorectal cancer patients. They suffer with changes in intestinal habits and other physical symptoms which impair postoperative performance. Our study has observed positive correlation between anxiety and gastrointestinal symptoms, although presenting low scores in the EORTC QLQ-CR38 questionnaire. These symptoms may be related to psychological problems persisting along the years, even after the disease is controlled ${ }^{28}$, that is, there is somatization or clinical manifestation of anxiety.

Our study has some limitations, such as the type of probabilistic sample, the small number of patients and the transversal retrospective design which does not evaluate cause and effect relationship, although allowing the formulation of hypotheses based on observed associations. New prospective studies should be carried out by following patients and the impact of disease and treatment along time.

\section{CONCLUSION}

Mid and low rectal cancer patients after surgical treatment have poorer symptoms and functions scores in the evaluation of $\mathrm{QL}$, which become more evident when associated to pain intensity, depression and anxiety. These data suggest the multifactorial origin of the problem, indicating the need for approaches in several fields: physiological, cognitive, emotional and social.

\section{REFERENCES}

1. Aaronson N, Ahmedzai S, Bergman B, Bullinger M, Cull A, Duez n, et al. The European Organization for Research and Treatment of Cancer QLQ-C30: a quality-of-life instrument for use in international clinical trials in oncology. J Nat Cancer Instit. 1993;85:3365-76.

2. Cornish JA, Tilney HS, Heriot AG, Lavery IC, Fazio VW, Tekkis PP. A metaanalysis of quality of life for abdominoperineal excision of rectum versus anterior resection for rectal cancer.Ann SurgOncol. 2007;14(7):2056-68.

3. Cunha JA. -Manual da Versão em Português das Escalas de Beck. Casa do Psicologo, São Paulo, 2001. 171 p.

4. Ferlay J, Shin HR, Bray F, Forman D, Mathers C, Parkin DM. Estimates of worldwide burden of cancer in 2008: GLOBOCAN 2008. Int J Cancer. 2010;127(12):2893-917.

5. Fucini C, Gattai R, C.Urena,L.Bandettini, C.Elbetti. Quality of among fiveyear survivor after treatment for very low rectal cancer wint or without a permanent abdominal stoma. Ann SurgOncol. 2008;15(4):1099-106.
6. Glynne-Jones R, Mathur P, Elton C, Train M. Multimodal treatment of rectal cancer. Best Practice Res ClinGastroenterol. 2007;21(6):1049-70.

7. Gorestein C, Andrade I. Validation of Portuguese version of the Beck Depression Inventory and the State-Trait Anxiety in Brazilian Subjects. Braz J Med Biol Res. 1996;29:453-7.

8. GosselinkMp, BusschbachJj, Dijkhuis Mc, Stassen Ip, Hop Hc, Schouten Wr. Quality of life after total mesorectal excision for rectal cancer. Colorectal Dis. 2004(8):15-22.

9. INSTITUTO NACIONAL DO CÂNCER. Estimativa 2012-incidëncia de cäncer no brasil. 2012 [10/02/2012]; Available from: < httpwww.inca. gov.br/estimative/2012/versãobfinal.pdf>.

10. Jürgen $M$, Des CW. Sphincter preservation for distal rectal cancer - a goal worth achieving at all costs?World J. Gastroenterol. 2011;17(7): 855-861.

11. MacFarlane JK, Ryall RD, Heald RJ.Mesorectal excision for rectal cancer. Lancet. 1993;341(8843):457-60.

12. Martinez JE, Grassi DC, Marques LG. Análise da aplicabilidade de três instrumentos de avaliação de dor em distintas unidades de atendimento: ambulatório, enfermaria e urgência.RevBrasReumatol 2011;51(4):299-308.

13. Matsushita T, Matsushima E, Maruyama M. Assessment of perioperative quality of life in patients undergoing surgery for gastrointestinal cancer. Supp Care Cancer. 2004;12:319-25.

14. Nuhu F, Odejide O, Adebayo K, Yusuf A. Psychological and physical effects of pain on cancer patients in Ibadan, Nigeria. African J Psychiatry. 2009(2):64-70.

15. Palmer G, Martling A, Lagergren P, Cedermark B, Holm T. Quality of life after potentially curative treatment for locally advanced rectal cancer. Ann SurlOncol. 2008;15(11):3109-17.

16. Pereira $M$, Fiquereido A. Depressão, ansiedade, e stress pós-traumático em doentes com cancro colo-retal. ONCONEWS. 2008;5:11-9.

17. Pietrzak L, Bujko K, Nowacki MP, Kepka L, Oledzki J, Rutkowski A, et al. Quality of life, anorectal and sexual functions after preoperative radiotherapy for rectal cancer: report of a randomized trial. Radiotherapy and oncology : J EurSocTherapRadiolOncol. 2007;84(3):217-25.

18. Pucciarelli S, Del Bianco P, Efficace F, Toppan P, Serpentini S, Friso ML, et al. Health-related quality of life, faecal continence and bowel function in rectal cancer patients after chemoradiotherapy followed by radical surgery. Supp Care Cancer. 2010;18(5):601-8.

19. Rauch P, Miny J, Conroy T, Neyton L, Guillemin F. Quality of life among disease-free survivors of rectal cancer. J ClinOncol. 2004;22(2):354-60.

20. Ristvedt SL, Trinkaus KM. Trait anxiety as an independent predictor of poor health-related quality of life and post-traumatic stress symptoms in rectal cancer. Br J Health Psychol. 2009;14(4):701-15.

21. Robison M, Edwars J, Iyengar S, Bymater F, Clark M, Katon w. Depression and Pain. PsychiatrDanub. 2010;22(1):111-3.

22. Santos J, Mota D, Pimenta C. Comorbidade, fadiga e depressão em pacientes com cancer colo retal RevEscEnferm USP. 2009;43(4):909-14.

23. Serpentini S, Del Bianco P, Alducci E, Toppan P, Ferretti F, Folin M, et al. Psychological well-being outcomes in disease-free survivors of mid-low rectal cancer following curative surgery. Psycho-oncology. 2011;20(7):706-14

24. Souza R, et al. Avaliação da qualidade de vida de doente de carcinoma retal, submetidos a ressecção com preservação esfincteriana ou à amputação abdomino-perineal. Rev Bras Coloproct 2005;25(3):235-40.

25. Sprangers MAS, Velde Ta, Aaronson Nk. The Construction and Testing of the EORTC Colorectal Cancer-specific Quality of Life Questionare Module (QLQ-CR38).Eur J Cancer. 1999;35(2):238-47.

26. Tavoli A, Mohagheghi MA, Montazeri A, Roshan R, Tavoli Z, Omidvari $S$. Anxiety and depression in patients with gastrointestinal cancer: does knowledge of cancer diagnosis matter? BMC Gastroenterol. 2007;7:28.

27. Teunissen S, Graeff da, Voest E. Are anxiety and depressed mood related to physical symptom? a study in hospitalized advanced cancer patients. Palliative Mdicine. 2007;21:341-6.

28. Tsunoda A, Nakao K, Hiratsuka K, Yasuda N, Shibusawa M, Kusano M. Anxiety, depression and quality of life in colorectal cancer patients. Intern J ClinOncol. 2005;10(6):411-7

29. Van Cutsem E, Dicato M, Haustermans K, Arber N, Bosset JF, Cunningham $D$, et al. The diagnosis and management of rectal cancer: expert discussion and recommendations derived from the 9th World Congress on Gastrointestinal Cancer, Barcelona, 2007. Annals of Oncology : official journal of the European Society for Medical Oncology / ESMO. 2008;19Suppl 6:vi1-8.

30. Zaza C, Baine N. Cancer pain and psychosocial factors: a critical review of the literature. J Pain Symptom Manag. 2002;24(5):526-42. 